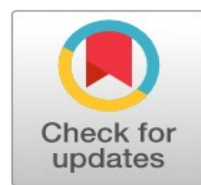

\title{
The relative importance of quality costs in Jordanian pharmaceutical manufacturing sector and their deficiencies
}

\author{
Sanaa Maswadeh *
}

Jadara Private University, Irbid, Jordan

\author{
Index Terms \\ Quality costs \\ Prevention costs \\ Appraisal costs \\ Internal failure costs \\ External failure costs.
}

Received: 30 October 2016

Accepted: 10 December 2016

Published: 27 February 2017

\begin{abstract}
The aim of study is to determine the relative importance of each of the elements of quality costs, classified to prevention costs, appraisal costs, internal failure costs, and external failure costs, and deficiencies related to these elements, in Jordanian pharmaceutical manufacturing sector. The sample was selected using simple random sampling with a sample size of 9 Jordanian pharmaceutical companies from population consisting of 24 companies at the end of 2015. A total of 50 questionnaires were distributed to quality and production managers in sample study; out of 50 questionnaires, only 40 were fit for analysis, one sample t-test was used to test the hypotheses of the study. The most important results of study were: awareness among the responses of study members about the importance of the elements of four dimensions of quality costs. The most deficiencies in the prevention cost elements related to failure of existing quality reference manual to match production specifications on continuous basis. And the most deficiencies in the appraisal cost elements involved in developing agreed standards for classifying products into good and defective or damaged according to the level of their quality. And showed the deficiencies in internal failure cost elements involved in estimating lost time costs on the rehabilitation products. And deficiencies in the external failure cost elements related to estimating costs of losing customers and decrease in market share because of customers' dissatisfaction of product quality. Finally, the study recommended Jordanian pharmaceutical manufacturing management increased their attention to quality system planning costs on continuous and permanent basis.
\end{abstract}

(c) 2017 The Author(s). Published by TAF Publishing.

\section{INTRODUCTION}

Quality has long been viewed as a prerequisite for building a competitive strategy to enable organizations confront with an intensified competition at domestic and global markets. In this context, quality cost has become critical to contemporary business organizations by focusing on the cost of quality dimensions, measurement, cost of compliance with quality standards, and the cost of failing to meet the quality requirements. Practical evidence from previous studies has shown that organizations apply quality cost accounting systems that seek toward zero defect production, thereby cutting down production costs, increasing productivity and maximizing profitability. The saving accrued from cost cut down will be transferred to customers in form of lower price, thereby increasing sales and profits (Mehsib, 1994; Intan, 2016). Quality costs include the costs incurred due to the repetition of certain procedures, testing, warranties and other similar activities related to a defective product or process. One of the reasons why measuring quality costs is justified lies in the fact that prevention is cheaper than fixing errors. The benefits of identification, quantification and monitoring of quality costs in companies are manifold.

\footnotetext{
* Corresponding author: Sanaa Maswadeh

${ }^{\dagger}$ Email: mmsana2005@yahoo.com
} 
Freiesleben (2008) stated that modern concept of quality costing of a product or process, as a performance measure, reflects what has transpired to the product after it has been dispatched to the customer and not on product scrap and rework. According to Yang (2008), the benefits of an accurate measurement of quality costs include focusing upon areas of poor performance that need improvement, assisting in the overall control of quality, and raising the firm's competitive advantage through higher quality and lower costs. Lari \& Asllani (2013) and Krisnawati, Perangin-Angin, Zainal \& Suardi (2016) found that after the quality cost system was adopted, there was a decrease in customer complaints, rework and scrap, warranty expenditures, and failure costs, and an increase in sales volume. Rasamanie \& Kanapathy (2011) also concluded that the implementation of a quality cost reporting system definitely brings benefits to the organization. The cost of quality is part of the costing system in organizations. Quality and continuous improvement formed the momentum for organizations to achieve a competitive edge by focusing on the quality cost and their elements which are divided into: prevention costs, appraisal costs, internal failure costs and external failure costs. In this perspective, quality has no longer been associated with high cost; but rather viewed as contributing to cutting down costs, and increased profitability for organization by improving product quality, and controlling quality in terms of cost, profits, and risks through meeting customer needs and expectations and monitoring quality in a way to strike balance between quality and expected returns. So this study came to focus on the quality costs and the relative importance of their elements, in order to direct management attention to these elements to avoid poor quality, and finding out best practices to reduce deficiencies in the quality process which form the factors that expectedly improve performance of the organization and increase its competitiveness.

\section{Problems of the Study}

The high ratio of cost quality to total production costs impacts profitability. In 1978, the costs associated with the quality in the UK were estimated at $\$ 10$ milliard accounting for $10 \%$ of the gross national UK product GNP, and there were many immeasurable quality losses reflecting misuse of available resources, an increase of costs or the hidden quality costs as represented by customer attrition, poor reputation, and decrease of the market share, which are estimated at $30 \%$ of production costs. Then quality cost as recorded in the accounting books does not reflect the real costs (Arabi, 1997). Despite the increased interest in quality issues, the costs associated with quality were not sufficiently studied in comparison with other costs related to other functions such as production, marketing, distribution costs, etc. As a result there was little information about the quality activity costs, in addition to the difficulty of controlling such costs, and comparing them with the costs and losses associated with poor quality, customer dissatisfaction, and the resulting low revenues, profits and poor reputation of the organization all enhanced the call for identifying the relative importance of each of the quality cost elements including prevention costs, appraisal costs, internal failure costs and external failure costs given their role in directing data towards performance improvement and achieving the organization's competitive edge. Based on the previous discussion, the problem addressed by the current study can be coined in the following main question: what is the relative importance of quality cost elements and related deficiencies in Jordanian pharmaceutical companies?

The previous main question leads to the following questions:

1- What is the relative importance of prevention cost elements and related deficiencies in Jordanian pharmaceutical companies?

2- What is the relative importance of appraisal cost elements and related deficiencies in Jordanian pharmaceutical companies?

3- What is the relative importance of internal failure cost elements and related deficiencies in Jordanian pharmaceutical companies?

4- What is the relative importance of external failure cost elements and related deficiencies in Jordanian pharmaceutical companies?

\section{Hypotheses of the Study}

This study aimed to test the following hypotheses:

1- There is no interest related to the elements of prevention costs in Jordanian pharmaceutical companies.

2- There is no interest related to the elements of appraisal costs in Jordanian pharmaceutical companies.

3- There is no interest related to the elements of internal failure costs in Jordanian pharmaceutical companies.

4- There is no interest related to the elements of external failure costs in Jordanian pharmaceutical companies.

\section{Significance of the Study}

The commitment with quality costs improves productivity by eliminating barriers on the production lines, and trans- 
ferring the effort exhausted in remedy of defects to increase productivity by manufacturing good quality and new products. Ultimately, this will improve the performance of organization, cut down production cost and increase profits. Furthermore, quality decision is significantly strategic because in the final analysis it targets cost saving with conformity to quality requirements. However, the interest in quality costs and their elements at the Jordanian pharmaceutical industrial companies is critical, considering their important role in achieving objectives and goals, and improving strategic position on the local and global market.

\section{Contribution of the Study}

The current study adds further to the knowledge field on quality costs and to demonstrate the relative importance of prevention costs, appraisal costs, internal failure costs, and external failure costs and related deficiencies at the pharmaceutical manufacturing sector that is strictly controlled by the government regulations to comply with the quality standards. Keeping this importance in mind, the organizations need to adopt cost reduction, quality and performance improvement policies so as to become more competitive on the local and global markets, thereby maintaining and increasing their share in markets.

\section{LITERATURE REVIEW AND THEORETICAL FRAME- WORK}

Quality cost has been defined differently by different authors, and whether should be measured or not, and many concepts are used to describe quality costs. Some authors viewed quality cost as costs of compliance with design specifications. The concept of quality costs has extended to include quality cost after delivering product to customer. Some studies indicated to the hidden costs associated with losses caused by attrition of the market share, poor reputation as a result of poor quality.

Thomas \& Harold (1997) defined quality costs as being representative of the sacrifice by the organization to produce good quality products or services that satisfy customer needs. Schroeder, Clark \& Cathey (2014) investigated the possibility of cost control over value chain stages, arguing that the quality cost is "the costs expensed to acquire the quality value of the product and avoid defects and faults over the production process stages". Rodchua (2006) referred to quality cost as the "costs caused by faults or defects in the product or the excessive cost to produce good quality in addition to losses resulting from poor quality and customer dissatisfaction".
The previous literature reviewed, especially Russel \& Taylor (1998) was found almost in agreement with the functional classification of quality costs: prevention costs, appraisal costs, internal failure costs, and external failure costs. The prevention costs and appraisal costs are considered as conformity costs. Both the internal and external failure costs are considered as non-conformity costs. Included in these elements are other sub-elements that relatively differentiate based on the company activity, and are associated by an interrelated relationship. It is worth to note that these elements are classified depending on nature of each industry or activity of the organization and administrative and operative regulations.

However, the assignment of cost size into each category is not clear cut, and considered as a judgmental matter based on personal discretion of the data analyst. Drawing common sense definition of quality costs, existence of high quality product depends on two dimensions: first quality design and quality implementation. Garrison, Noreen \& Brewer (2014) defined prevention costs as the costs expensed to prevent introducing a product or service that is not matching with the quality requirements. The prevention costs, in this meaning, associate with prevention of faults and avoidance of poor quality.

Further defined appraisal costs as being the entire costs related to planned activities to examine and appraise a product over the various production phases' pre, through, and post production in order to make sure the production process is going as planned, and the produced units conform with the quality requirements before the delivery to customer. Rajeev, Rajiv \& Anish (2014) defined internal failure costs as the costs associated with losses from non-conformity products or services with quality requirements that were detected before delivery to customer. Also defined external failure costs as the costs associated with losses from non-conformity products or services with quality requirements that are detected after being delivered to customer. External failure costs include two sets of costs: explicit costs represented by the cost of responding to customer complaints during the warranty period, claim cases, allowances offered to customers, etc., whereas hidden costs represent the opportunity cost for losing customers and sales, caused by poor quality.

Anderson \& Sedatole (1998) considered that the current measure of quality costs depends on the concept of quality defined as conformity with standards which is viewed as the essential source of quality costs. Attieh (1996) argued that having a control and monitoring system of both hid- 
den and explicit quality provides the company with many advantages such as success of quality improvement programs, savings, more profitability, commitment to social responsibility and feedback about the quality costs. Shami (1999) mentioned measuring and reporting quality costs contribute to lower cost through more effective control thereby reducing the probability of defective products being delivered to customers, hence increasing the number of new customers. Sower \& Quarles, (2003) mentioned that measuring quality in terms of cost instead of counting defects, made using performance measures by managers easier and enabled continuous improvement of performance. Gado \& Kamel (2004) found that interest with quality costs contributes the link between the organizational strategic goals and continuous improvement of product quality if the quality cost elements data were saved at the organization's database.

Rodchua (2006) investigated which of quality cost elements have priority to reduce cost and found that prevention costs, and external failure costs have priority to reduced total costs. Responses were in agreement that the prevention costs ensure tools and training to save waste in the production process. Hussan \& Mand (2001) mentioned the importance of the interrelationship between quality cost elements that indicates where efforts should be directed to reduce quality costs and improve quality, and found failure costs mostly represent $50 \%$ of the total quality costs. Plunkett \& Dale (1988) showed that however many approaches were found to describe the relationship between quality cost elements, they lack accuracy which cast a sort of doubt on the concept of optimal quality level.

Albright \& Roth (1992) mentioned that the quality cost elements are interrelated, where the costs invested in the prevention and appraisal costs would reduce both internal and external failure costs in amount exceeding the originally invested costs, thereby achieving return on investment. Diallo, Khan \& Vail (1994) showed that reporting real quality costs is considered an instrument to cut down cost by employing the positive elements of the quality costs to serve the continuous improvement in the production processes, and the role of such costs by using it in the return on investment computation that links investment in quality programs and fault prevention activities with the return obtained from cutting down poor quality costs.

Abu-Amer (2015) discussed that more interest is given by companies to quality costs (prevention costs, appraisal costs, internal failure costs, and external failure costs) and reporting in the financial statements plays a significant role in cost reduction, increasing revenues, with positive effects on the strategic performance of the Palestinian industrial companies. Shibley \& Safaiddin (2014) proposed a model depending on the relationship between quality cost elements to demonstrate the weaknesses and strengths in performance of Iraqi companies by linking quality outcomes with continuous improvement of company's performance and productivity. Hamouda (2014) revealed high awareness among managers at the Palestinian Industrial companies to the significance of quality costs' measurement (prevention costs, appraisal costs, internal failure costs and external failure costs) and the expected advantages from applying them.

Nahawi (2013) found a statistically significant effect of the application of total quality management integrated with quality cost management on the improvement of Jordanian industrial company's performance. Jafari \& Rodchua (2014) showed that the organizational factors were among the most significant internal factors to help quality cost systems to succeed in the real-estate companies in Iran, in addition to external environmental factors where the organization operates.

Hansen \& Mowen (2006) showed that Turkish industrial companies were less interested in measuring the quality costs, and monitoring quality system was ineffective in these companies which negatively affect their ability to reduce costs and increase competitiveness on the market. On the other hand, Teli, Bhushi \& Surange (2012) revealed that quality costs related to non-conformity with quality requirements (internal failure costs and external failure costs) assisted Indian car manufacturing industry companies analyze operational costs more effectively and reduced pre-production defects, in addition to scheduling interruption, and focusing on essential issues that avoid production interruption and achieve better quality.

Rajeev et al (2014) found that quality costs related to prevention activities were the most influential on return on investment, in addition to the impact of quality costs related to prevention activities on reduction of failure costs. Rasamanie \& Kanapathy (2011) revealed that most difficulties encountered by Malaysian companies when applying quality costs were ineffective coordination among organizational levels, and the major benefit of the application of quality costs was improvement of product or service quality, and reduction of failure in the company. Kim \& Nakhai (2008) stated the conformity with standards and specifications required by total quality management and quality costs related to prevention activities lead to continuous 
improvement of product quality and reduction of cost of internal and external failure of product.

\section{RESEARCH METHODOLOGY}

In order to achieve the primary objectives of this study, a theoretical literature review has been done in order to determine each element related to quality costs classified to prevention costs, appraisal costs, internal failure costs, and external failure costs. Questionnaire was chosen as the method by which the survey had to be conducted.

\section{Population and Sample of the Study}

The population of the study consists of 24 Jordanian pharmaceutical companies. 9 Companies were selected as a sample using simple random sampling method. A total of 50 questionnaires were distributed to quality and production managers who have good educational background related to quality assurance and quality cost concepts. Out of 50 questionnaires, only 40 questioners were fit for analysis.

\section{Instrumentation}

The data of this study were obtained through a survey; questionnaires were distributed to 9 Jordanian pharmaceutical companies. The questionnaire is divided into two sections. The first section includes the demographic characteristics of the respondent (age, certification, educational level, and expertise).

In the second section, 35 items of the four categories of quality costs were included, where respondents were asked to indicate the level of interest toward these 35 items on a five-point Likert Scale, ranging from (1 - less interested), ( 2 - somewhat interested), (3 - middle interested), (4 - interested) and (5 - very interested); the questionnaire was designed referring to literature review of different studies.

\section{Procedure}

The questionnaires were answered by the quality and production managers of Jordanian pharmaceutical companies. The questionnaires were distributed to 50 respondents at 9 different pharmaceutical companies selected by using simple random sampling method for a period of 2 months (December 2015 to January 2016). The questionnaires were distributed with the help of enumerators.

\section{Statistical Method}

The responses obtained from the survey were tested for internal consistency and reliability using Cronbach's alpha tests. The study tested the hypotheses using one sample t-test by comparing the test value calculated with the mean for the study sample value for all of the 35 items listed in the questionnaire. As the scale of the questionnaire was graded using the five point Likert scale starting from 1 to 5 , then the study calculated the relative importance of each item by dividing item mean to the highest point on Likert scale which is five, ranging from (20\% less interested), $(40 \%$ somewhat interested), (60\% - middle interested), (80\% interested), and (100\% - very interested). The test value of the comparison is $3((5+4+3+2+1) / 5))$ or $60 \%(3 / 5)$. Hence, if the level of significance is less than or equal to $(0.05)$ at $95 \%$ confidence level, there are statistically significant differences from the test value (3) and the mean for the study sample value for each item and each category of quality costs was included.

However, if the level of significance is greater than (0.05), then there are statistically no significant differences from the test value (3) and the mean for the study sample value for each item and each category of the quality costs was included. Consequently, the researcher would accept the alternative hypothesis if the significance level is equal to or less than (0.05) in each category of quality costs included, and accept the null hypothesis if the significance level is greater than $(0.05)$ in each category of quality costs included.

\section{STATISTICAL RESULTS}

This section includes analysis and discussion of the study data and empirical study results in light of the study hypotheses. The data were analyzed and the Coefficient alpha, as suggested by Peter (1979), was calculated to measure the reliability of the questionnaire.

The alpha values in this study showed high reliability, for the whole questionnaire (0.80) and each of the related items of cost quality: prevention costs (0.83), appraisal costs (0.79), internal failure costs (0.77), and external failure costs $(0.74)$. These findings prove that the questionnaire is a valid instrument to evaluate relative importance of quality costs in Jordanian pharmaceutical manufacturing sector.

The statistical analysis to demographic characteristics of the respondents (age, certification, educational level, and expertise) showed qualified and expert respondents by using descriptive statistics such as frequencies. Results from one-sample t-test regarding the first hypothesis "There is no interest related to the elements of prevention costs in Jordanian pharmaceutical companies" were tabulated and presented by table (1). Table (1) shows that all the items 
measuring interest related to the elements of prevention costs in Jordanian pharmaceutical companies had means higher than the test value $(M=3)$ at a statistical significance level $(\alpha \leq 0.05)$, indicating interest related to the elements of prevention costs in Jordanian pharmaceutical companies from view of the individual study sample.

TABLE 1. Relative importance of each cost related to the elements of prevention costs (The degree of interest related to the elements of prevention costs)

\begin{tabular}{|c|c|c|c|c|c|}
\hline Items & Mean & Relative Importance & Std Deviation & T-Value & Sig \\
\hline Studying and monitoring the design of old and new product before production. & 4.04 & $81 \%$ & 1.01 & 8.72 & 0.00 \\
\hline Engineering manufacturing operations at all stages from the beginning of product design to completion. & 4.02 & $80 \%$ & 1.06 & 8.22 & 0.00 \\
\hline Investment in quality measurement and control equipment. & 3.96 & $79 \%$ & 0.91 & 9.44 & 0.00 \\
\hline Putting sufficient investment in the necessary quality improvement equipment. & 3.92 & $78 \%$ & 0.80 & 9.72 & 0.00 \\
\hline Improving quality projects such as education and training programs on quality. & 3.89 & $78 \%$ & 0.83 & 9.07 & 0.00 \\
\hline Improving total quality management courses and ISO certificates for their employees to keep them following total quality requirements on regular and continuous basis. & 3.79 & $76 \%$ & 0.86 & 8.24 & 0.00 \\
\hline Studying suppliers and their quality procedures before dealing with them. & 3.75 & $75 \%$ & 0.78 & 8.63 & 0.00 \\
\hline Examining the quality of raw materials and differentiation among them before buying them from suppliers. & 3.65 & $73 \%$ & 0.75 & 8.14 & 0.00 \\
\hline Concerned with the cost of preparation of reports and summaries of activities for data quality to the authorities parties. & 3.41 & $68 \%$ & 0.76 & 8.97 & 0.00 \\
\hline Concerned with the costs of development and planning of quality systems and review their effectiveness. & 3.38 & $68 \%$ & 0.89 & 7.40 & 0.01 \\
\hline Developing manual quality as a reference for matching product specifications on continuous basis. & 3.21 & $64 \%$ & 0.74 & 7.92 & 0.04 \\
\hline The arithmetic mean of the total items related to the elements of prevention costs. & 3.73 & $75 \%$ & 0.83 & 9.07 & 0.00 \\
\hline
\end{tabular}

Also table (1) shows, the most interest of prevention costs elements related with "studying and monitoring the design of old and new product before production", and costs related with "engineering manufacturing operations at all stages from the beginning of product design to completion" with the means are 4.04, 4.02 respectively, and relative importance approximately $81 \%, 80 \%$ respectively and a significance level is equal to or less than (5\%). Also table (1) shows the most deficiencies of the prevention costs elements related to "concerned in the costs of development and planning of quality systems and review their effectiveness" and costs related with "developing manual quality as a reference for matching product specifications on continuous basis" with the means of 3.38, 3.21 respectively, and relative importance approximately $68 \%, 64 \%$ respectively and a significance level equal to or less than (5\%). Table (1) shows one-sample t-test results to the overall items related to the first hypothesis had mean score $(\mathrm{M}=3.73)$ and relative importance approximately $75 \%$, at a significant level $(0.00)$ which is less than $\alpha \leq 0.05$, implying a significant interest related to the elements of prevention costs in Jordanian pharmaceutical companies, and allows rejecting the null hypothesis and accepting the alternative hypothesis, "there is interest related to the elements of prevention costs in Jordanian pharmaceutical companies". And this result agrees with (Pires, Cociorva, Saraiva, Novas \& Rosa, 2013; Kim \& Nakhai, 2008) studies. Results from one-sample t-test regarding the second hypothesis "There is no interest related to the elements of appraisal costs in Jordanian pharmaceutical companies" were tabulated and presented by table (2).

TABLE 2 . Relative importance of each cost related to the elements of appraisal costs (The degree of interest related to the elements of appraisal costs)

\begin{tabular}{|c|c|c|c|c|c|}
\hline Items & Mean & Relative Importance & Std Deviation & T. Value & Sig \\
\hline Concerned in the inspection services and maintenance of machines and production lines to ensure production quality. & 4.10 & $82 \%$ & 0.94 & 7.2 & 0.00 \\
\hline Interested in the costs of raw material not matching specifications and received from suppliers. & 3.89 & $78 \%$ & 0.83 & 5.89 & 0.00 \\
\hline Examining and checking samples of work in process during the production process and before they move from one stage to the other. & 3.66 & $73 \%$ & 1.01 & 4.11 & 0.00 \\
\hline Concerned with tweaking and testing packages' costs and reliability of the containers prior to delivery to the customers. & 3.47 & $69 \%$ & 0.85 & 3.37 & 0.00 \\
\hline Evaluating and checking inventory costs and making sure of the safety and health of products' storage procedures. & 3.33 & $67 \%$ & 0.88 & 3.11 & 0.00 \\
\hline Examining the internal control operations procedures on the stages of production. & 3.28 & $66 \%$ & 0.98 & 3.14 & 0.03 \\
\hline Developing specific criteria for classifying products into good and defective or damaged according to the level of quality. & 3.24 & $65 \%$ & 0.88 & 3.18 & 0.04 \\
\hline The arithmetic mean of the total items related to the elements of appraisal costs. & 3.68 & $74 \%$ & 0.86 & 8.17 & 0.00 \\
\hline
\end{tabular}


Table (2) shows that all the items measuring interest related to the elements of appraisal costs in Jordanian pharmaceutical companies had means higher than the test value $(M=3)$ at a statistical significance level $(\alpha \leq 0.05)$, indicating interest related to the elements of appraisal costs in Jordanian pharmaceutical companies from view of the individual study sample.

Also table (2) shows, the most interest of appraisal costs elements related with "concerned with the costs of maintenance and inspection equipment used in quality control on a regular basis" and costs related with "concerned with the inspection services and maintenance of machines and production lines to ensure production quality", with the means of $4.15,4.10$, respectively, and relative importance approximately $83 \%, 82 \%$ respectively and a significance level equal to or less than (5\%). Also table (2) shows the most deficiencies of the appraisal costs elements related to "Examining the internal control operations procedures on the stages of production" and costs related with "developing specific criteria for classifying products into good and defective or damaged according to the level of quality" with the means of 3.28, 3.24 respectively, with relative importance approximately $66 \%, 65 \%$ respectively and a significance level equal to or less than (5\%). Table (2) shows one-sample t-test results to the overall items related to the second hypothesis had mean score $(\mathrm{M}=3.68)$ and relative importance approximately $74 \%$, at a significance level $(0.00)$ which is less than $\alpha \leq 0.05$, implying a significant interest related to the elements of appraisal costs in Jordanian pharmaceutical companies, and allows rejecting the null hypothesis and accepting the alternative hypothesis, "there is interest related to the elements of appraisal costs in Jordanian pharmaceutical companies". And this result agrees with (Rajeev et al., 2014; Rodchua, 2006). Results from one-sample t-test regarding the third hypothesis "There is no interest related to the elements of internal failure costs in Jordanian pharmaceutical companies" were tabulated and presented by table (3).

TABLE 3 . Relative importance of each cost related to the elements of internal failure costs (The degree of interest related to the elements of internal failure costs)

\begin{tabular}{|c|c|c|c|c|c|}
\hline Items & Mean & Relative Importance & Std Deviation & $\mathrm{T}$ - Value & Sig \\
\hline Study the causes leading to inferior production quality (product failure). & 3.88 & $78 \%$ & 0.29 & 6.34 & 0.00 \\
\hline Studying proportion of damaged units (scrap) which cannot be avoided. & 3.82 & $76 \%$ & 0.80 & 9.72 & 0.00 \\
\hline Concerned with wasted materials or lost during production. & 3.66 & $73 \%$ & 0.42 & 8.42 & 0.00 \\
\hline Breakdowns maintenance and production process stop and the resulting lost time. & 3.64 & $73 \%$ & 0.51 & 4.23 & 0.00 \\
\hline Lost time of rehabilitation products. & 3.33 & $67 \%$ & 1.07 & 2.93 & 0.02 \\
\hline The arithmetic mean of the total items related to the elements of internal failure costs. & 3.66 & $73 \%$ & 0.74 & 7.92 & 0.00 \\
\hline
\end{tabular}

Table (3) shows that all the items measuring interest related to the elements of internal failure costs in Jordanian pharmaceutical companies had means higher than the test value $(M=3)$ at a statistical significance level $(\alpha \leq 0.05)$, indicating interest related to the elements of internal failure costs in Jordanian pharmaceutical companies from view of the individual study sample.

Also table (3) shows, the most interest of internal failure elements related with "study the causes leading to inferior production quality (product failure)" and costs related with "Studying proportion of damaged units (scrap) which cannot be avoided", with the means of 3.88, 3.82, respectively, and relative importance approximately $78 \%, 76 \%$ respectively and a significance level equal to or less than (5\%). Also table (3) shows the most deficiencies of the internal failure costs elements related to "arising from re-enter data due to entry errors" and costs related with "lost time of rehabilitation products" with the means of $3.57,3.33$ respectively, with relative importance approximately $71 \%$, $67 \%$ respectively and a significance level equal to or less than (5\%). Table (3) shows one-sample t-test results to the overall items related to the third hypothesis had mean score $(M=3.66)$ and relative importance approximately $73 \%$, at a significance level $(0.00)$ which is less than $\alpha \leq 0.05$, implying a significant interest related to the elements of internal failure costs in Jordanian pharmaceutical companies, and allows rejecting the null hypothesis and accepting the alternative hypothesis, "there is interest related to the elements of internal failure costs in Jordanian pharmaceutical companies". And this result agrees with different studies 
such as Hilmi, and Zulkuf (2015), Abu-Amer (2015) and Freiesleben (2008). Results from one-sample t-test regarding the fourth hypothesis "There is no interest related to the elements of external failure costs in Jordanian pharmaceutical companies" were tabulated and presented by table (4).

TABLE 4 . Relative importance of each cost related to the elements of external failure costs (The degree of interest related to the elements of external failure costs)

\begin{tabular}{|c|c|c|c|c|c|}
\hline Items & Mean & Relative Importance & Std Deviation & T-Value & Sig \\
\hline Responding to customer complaints due to a defect in the products. & 3.67 & $73 \%$ & 0.89 & 6.37 & 0.00 \\
\hline Discount and allowances granted to customers during the period of validity of product. & 3.62 & $72 \%$ & 0.90 & 5.95 & 0.00 \\
\hline Return products from customers as a result of the failure of the specification. & 3.58 & $72 \%$ & 0.98 & 5.08 & 0.00 \\
\hline Borne by the customer after expiration date. & 3.44 & $69 \%$ & 1.01 & 3.75 & 0.00 \\
\hline Loss of goodwill as a result of the failure of the specifications. & 3.36 & $67 \%$ & 1.07 & 2.88 & 0.01 \\
\hline Declining company market share as a result of the failure of the specifications. & 3.33 & $67 \%$ & 1.07 & 2.63 & 0.01 \\
\hline Losing customers due to customer dissatisfaction with the quality. & 3.27 & $65 \%$ & 0.95 & 1.49 & 0.04 \\
\hline The arithmetic mean of the total items related to the elements of external failure costs. & 3.47 & $69 \%$ & 1.01 & 3.75 & 0.00 \\
\hline
\end{tabular}

Table (4) shows that all the items measuring interest related to the elements of external failure costs in Jordanian pharmaceutical companies had means higher than the test value $(M=3)$ at a statistical significance level $(\alpha \leq 0.05)$, indicating interest related to the elements of external failure costs in Jordanian pharmaceutical companies from view of the individual study sample. Also table (4) shows, the most interest of external failure costs elements related with "responding to customer complaints due to a defect in the products." and costs related with "discount and allowances granted to customers during the period of validity of product", with the means of $3.67,3.62$, respectively, and relative importance approximately $73 \%, 72 \%$ respectively and a significance level equal to or less than (5\%). Also table (4) shows the most deficiencies of the external failure costs elements related to "declining company market share as a result of the failure of the specifications" and costs related with "losing customers due to customer dissatisfaction with the quality" with the means of $3.33,3.27$ respectively, with relative importance approximately $67 \%, 65 \%$ respectively and a significance level equal to or less than (5\%).

Table (4) shows one-sample t-test results to the overall items related to the fourth hypothesis had mean score $(\mathrm{M}=3.47)$ and relative importance approximately $69 \%$, at a significance level $(0.00)$ which is less than $\alpha \leq 0.05$, implying a significant interest related to the elements of external failure costs in Jordanian pharmaceutical companies, and allows rejecting the null hypothesis and accepting the alternative hypothesis, "there is interest related to the elements of external failure costs in Jordanian pharmaceutical companies". And this result agrees with different studies such as (Hamouda, 2014; Abu- Amer, 2015; Gado \& Kamel, 2004; Kirlioğlu \& Çevik, 2013).

\section{CONCLUSION AND RECOMMENDATIONS}

The most prominent conclusion and recommendations were:

1- Measurement of quality costs demonstrates the existence of an opportunity for improving performance by showing wastage rates and the possibility of reducing them, and giving more attention to the elements of quality costs and their deficiencies and processing them.

2 - The elements of prevention costs and appraisal cost elements are the costs that can be regarded as a direct quality cost, they are pre-planned and that can be measured and obtained from the value chain of the various functions. And they are the costs of conformity or quality.

3- Increase spending on prevention costs will expect to reduce the need for appraisal costs resulting in the decrease of all kinds of failure costs. As proven benefit not only by reducing cost but through additional revenue from customer satisfaction and increase sales and achieve competitive position in the market.

4- Spending on prevention activities obtained revenue and benefit through low costs of failure and therefore lack of screening operations and testing and audits, but to a certain extent be prevention spending had revenues equivalent to failure and evaluation cost cuts if exceed this limit may incur additional costs generating no benefit from them.

5- Appraisal cost elements lead to reduction costs through pursuing cost assessment during and preproduction stages by examining and evaluating raw materials before receipt 
from the vendor and checking and testing samples of products under operating before they move from one stage to another, and by ensuring conforming products for specifications and following up assessment costs and inventory check and ensuring safety and validating storage procedures.

6- The reciprocal relationship between the elements of quality cost and the process of continuous quality improvement on the other hand, is considered as efficiency and effectiveness relationship. Efficiency of inputs is associated with the prevention and appraisal activities to achieve quality. Efficiency of outputs determines the level of quality achieved and low failure costs as a result of quality. Effectiveness is the amount of improving quality which will satisfy the customer.

The researcher recommends increased commitment and support from senior management to the culture of quality, and awareness of the quality cost elements, and reliance on accounting applications and administration to measure quality cost elements, and show concepts and interrelationships among these elements which helps in carefully planning quality cost elements, and makes accounting information of quality costs essential in the performance appraisal process and take appropriate decisions to improve the performance and quality. The companies must analyze the elements of the quality costs in proportion to the modern concepts of quality and lead to concentrate on the strategic direction by adopting the principle of valueaddition and focus on development instead of rectifying errors which achieves the essence of TQM in achieving continuous improvement which constitutes a source of success. It is hoped that this study assists companies to design a system for the measurement and disclosure of quality costs and their elements thereby increasing the ability of companies to identify variances, and control and monitor them, and taking necessary procedures to improve organization performance in order to achieve its vision, goals and strategy. Finally researcher mentioned that the ideas of this study are in the concept of defects which is based on the philosophy of continuous improvement in quality, which means the actual specifications match with planning, and without it cannot reach the lowest level of costs. And recommended to search in the most important financial and non-financial measures associated with quality costs and its strategic role in improving strategic performance of the companies.

\section{REFERENCES}

Abu- Amer, M. 2015. Relationship of quality costs and strategic performance: An empirical study of the industrial com- panies in the Gaza Strip. Unpublished Master's thesis, Islamic University, Gaza, IL.

Albright, T., \& Roth, H. 1992. The measurement of quality costs: An alternative paradigm. Accounting Horizons, 6(1): 15- 27.

Anderson, S.W., \& Sedatole, K. 1998. Designing quality into products: The use of accounting data in new product develop- ment. Accounting Horizons, 12(3): 213-220.

Arabi, M. 1997. Management of accounting methods to achieve total quality in industrial companies -Proposed portal. Jour- $\quad$ nal of the Scientific of the Economy \& Trade, 5(3): 213-251.

Attieh, T. 1996. Analyzing and measuring hidden quality costs. Journal of Cost the Arab Association for the Costs of Ad- ministrative \& Accounting, 2(1): 143-167.

Diallo, A., Khan, Z.U., \& Vail, C.F. 1994. Measuring the cost of investment in quality equipment. Strategic Finance, 76(2): 32-38.

Freiesleben, J. 2008. A proposal for an economic quality loss function. International Journal of Production Economics, 113(2): 1012-1024. DOI: 10.1016/j.ijpe.2007.12.005

Gado, S., \& Kamel, M. 2004. A proposed method to measure quality costs by using activities - Based cost management ap- $\quad$ proach. Scientific Journal of the Economy \& Trade, 3(5): 311-369.

Garrison, R.H., Noreen, E.W., \& Brewer, P.C. 2014. Managerial accounting. New York, NY: McGraw-Hill/Irwin.

Hamouda, K. 2014. The reality of quality costs in the Palestinian industrial companies. Unpublished Master's thesis, Islamic University, Gaza, IL.

Hansen, D.R., \& Mowen, M.M. 2006. Cost management: Accounting and control. New York, NY: South-Western College Pub. 
Hussan, T., \& Mand, A.O. 2001. Quality cost of fish and fishery product. Industrial Technology, 4(22): 1-6.

Intan, W.S. 2016. The analysis factors of experential marketing, product quality, and customer satisfaction of motor bike as a main transportation mode in Bandung-Indonesia. International Journal of Business \& Administrative Studies, 2(1): 6-8.

Kirlioğlu, H., \& Çevik, Z. 2013. Measuring and reporting cost of quality in a Turkish manufacturing company: A case study in electric industry. Journal of Economic \& Social Studies, 3(2), 87-101. D0I: 10.14706/JECOSS11326

Jafari, A., \& Rodchua, S. 2014. Survey research on quality costs and problems in the construction environment. Total Quality Management \& Business Excellence, 25(3-4): 222-234. DOI: 10.1080/14783363.2013.824715

Kim, S., \& Nakhai, B. 2008. The dynamics of quality costs in continuous improvement. International Journal of Quality \& Reliability Management, 25(8): 842-859. DOI: 10.1108/02656710810898649

Krisnawati, N., Perangin-Angin, L.K., Zainal, M., \& Suardi, I. 2016. Brand equity analysis and its impact on the loyal customer of local batik to develop its competitiveness (An empirical study of batik Banten in south tangerang). Journal of Admin- $\quad$ istrative \& Business Studies, 2(4): 189-207.

Mehsib, K. 1994. A proposed model for measuring and planning quality costs. Scientific Journal for Researches \& Studies, 1(4): 13-30.

Nahawi, M. 2013. The importance of integration between the total quality and cost management techniques to improve performance in Jordanian industrial companies. Unpublished Master's thesis, Middle East University, Amman, JO.

Lari, A., \& Asllani, A. 2013. Quality cost management support system: An effective tool for organisational performance im- $\quad$ provement. Total Quality Management \& Business Excellence, 24(3-4): 432-451.

DOI: $10.1080 / 14783363.2012 .733258$

Peter, J.P. 1979. Reliability: A review of psychometric basics and recent marketing practices. Journal of Marketing Re- search, 16(1): 6-17. DOI: $10.2307 / 3150868$

Pires, A.R., Cociorva, A., Saraiva, M., Novas, J.C., \& Rosa, Á. 2013. Management of quality-related costs. The case of Portuguese companies. Total Quality Management \& Business Excellence, 24(7-8): 782-796.

DOI: $10.1080 / 14783363.2013 .792993$

Plunkett, J.J., \& Dale, B.G. 1988. Quality costs: A critique of some 'economic cost of quality'models. The International Jour- $\quad$ nal of Production Research, 26(11): 1713-1726. DOI: 10.1080/00207548808947986

Rajeev, T., Rajiv, G.K., \& Anish, S. 2014. Categorization of quality cost: A study in engineering industry. Journal of Environ- mental Research \& Development, 8(3A): 846-849.

Rasamanie, M., \& Kanapathy, K. 2011. The implementation of cost of quality (coq) reporting system in malaysian manufac- turing companies, difficulties encountered and benefits acquired. International Journal of Business \& Social Science, $2(6):$ 243-247.

Rodchua, S. 2006. Factors, measures, and problems of quality costs program implementation in the manufacturing environJournal of Industrial Technology, 22(4): 1-6.

Russel, R.S., \& Taylor III, B.W. 1998. Operations management: Focusing on quality and competitiveness. Englewood Cliffs, NJ: Prentice Hall.

Schroeder, R.G., Clark, M.W., \& Cathey, J.M. 2014. Financial accounting theory and analysis: Text and cases. New York, NY: John Wiley and Sons.

Shami, M. 1999. A quantitative model to measure the cost of total quality to keep up with trade liberalization and support the competitive strategy of the enterprise. Journal of Business Studies \& Research, 3(1): 460-509.

Shibley, M., \& Safaiddin, U. 2014. Design of a quantitative model to analyze quality costs (structure, requirements, opera- tion). Journal of Qadisiyah of Administrative \& Economic Sciences, 16 (2): 33-49.

Sower, V.E., \& Quarles, R. 2003. Cost of quality: Why more organizations do not use it effectively. Paper presented at the ASQ World Conference on Quality and Improvement Proceedings American Society for Quality.

Teli, S.N., Bhushi, U.M., \& Surange, M.V. 2012. Assessment of Cost of poor quality in Automobile Industry. Assessment, 2(6): 330-336. 
Thomas, A., \& Harold, P. R. 1997. The measurement of quality costs: An alternative paradigm. Accounting Horizons, 3(3): $15-26$.

Yang, C.C. 2008. Improving the definition and quantification of quality costs. Total Quality Management, 19(3): 175-191. DOI: $10.1080 / 14783360701600563$

— This article does not have any appendix. — 